\title{
Educational Studies in Mathematics \\ Inappropriately applying natural number properties in rational number tasks: Characterizing the development of the natural number bias through primary and secondary education. --Manuscript Draft--
}

\begin{tabular}{|c|c|}
\hline \multicolumn{2}{|l|}{ Manuscript Number: } \\
\hline Full Title: & $\begin{array}{l}\text { Inappropriately applying natural number properties in rational number tasks: } \\
\text { Characterizing the development of the natural number bias through primary and } \\
\text { secondary education. }\end{array}$ \\
\hline Article Type: & Original Research \\
\hline Keywords: & $\begin{array}{l}\text { rational number; fraction; natural number bias; primary education; secondary } \\
\text { education }\end{array}$ \\
\hline Corresponding Author: & $\begin{array}{l}\text { Jo Van Hoof } \\
\text { KU Leuven } \\
\text { Leuven, BELGIUM }\end{array}$ \\
\hline \multicolumn{2}{|l|}{$\begin{array}{l}\text { Corresponding Author Secondary } \\
\text { Information: }\end{array}$} \\
\hline Corresponding Author's Institution: & KU Leuven \\
\hline \multicolumn{2}{|l|}{$\begin{array}{l}\text { Corresponding Author's Secondary } \\
\text { Institution: }\end{array}$} \\
\hline First Author: & Jo Van Hoof \\
\hline \multicolumn{2}{|l|}{ First Author Secondary Information: } \\
\hline \multirow[t]{3}{*}{ Order of Authors: } & Jo Van Hoof \\
\hline & Lieven Verschaffel \\
\hline & Wim Van Dooren \\
\hline \multicolumn{2}{|c|}{ Order of Authors Secondary Information: } \\
\hline Abstract: & $\begin{array}{l}\text { The natural number bias is known to explain many difficulties learners have with } \\
\text { understanding rational numbers. The research field distinguishes three aspects where } \\
\text { natural number properties are inappropriately applied in rational number tasks: density, } \\
\text { size, and operations. The overall goal of this study was to characterize the } \\
\text { development of the natural number bias across the span between } 4 \text { th and } 12 \text { th grade. } \\
\text { To achieve this goal, a comprehensive test was constructed to test } 4 \text { th to } 12 \text { th graders' } \\
\text { natural number bias. This test was administered to } 1343 \text { elementary and secondary } \\
\text { school students. Results showed that an overall natural number bias could be found. } \\
\text { This bias appeared to be equally strong in tasks with decimal numbers and tasks with } \\
\text { fractions. Moreover, the natural number bias was weakest in size tasks, somewhat } \\
\text { stronger in operations tasks, and by far the strongest in density tasks. An overall } \\
\text { decrease of the strength of the natural number bias - but no disappearance except for } \\
\text { size tasks - could be found with grade. }\end{array}$ \\
\hline
\end{tabular}



development of the natural number bias through primary and secondary education.

Jo Van Hoof*, Lieven Verschaffel*, and Wim Van Dooren*

* Centre for Instructional Psychology and Technology, University of Leuven, Dekenstraat 2, 3000 Leuven, Belgium

Corresponding author: jo.vanhoof@ppw.kuleuven.be; +3216 326205

\begin{abstract}
The natural number bias is known to explain many difficulties learners have with understanding rational numbers. The research field distinguishes three aspects where natural number properties are inappropriately applied in rational number tasks: density, size, and operations. The overall goal of this study was to characterize the development of the natural number bias across the span between $4^{\text {th }}$ and $12^{\text {th }}$ grade. To achieve this goal, a comprehensive test was constructed to test $4^{\text {th }}$ to $12^{\text {th }}$ graders' natural number bias. This test was administered to 1343 elementary and secondary school students. Results showed that an overall natural number bias could be found. This bias appeared to be equally strong in tasks with decimal numbers and tasks with fractions. Moreover, the natural number bias was weakest in size tasks, somewhat stronger in operations tasks, and by far the strongest in density tasks. An overall decrease of the strength of the natural number bias - but no disappearance except for size tasks - could be found with grade.
\end{abstract}

Keywords: rational number, fraction, natural number bias, primary education, secondary education 


\section{Introduction}

A good understanding of rational numbers is an essential part of mathematical literacy, which is not only important in learners' school career, but also in their everyday experiences. An illustration of the predictive relation between early knowledge of rational numbers and later mathematics achievement can be found in the longitudinal study of Siegler et al. (2012). They found that learners' rational number knowledge in the $5^{\text {th }}$ grade predicted their mathematical achievement in high school, even after taking into account reading achievement, IQ, working memory, whole number knowledge, family income, and family education. Although a good rational number understanding is found to be very important, many people have trouble understanding the different aspects of rational numbers (Cramer, Post, \& delMas, 2002; Mazzocco \& Devlin, 2008; Vamvakoussi, Van Dooren, \& Verschaffel, 2012; Vamvakoussi \& Vosniadou, 2004). Even many teachers struggle with the understanding of rational numbers (Clarke \& Roche, 2009; Post, Cramer, Behr, Lesh, \& Harel, 1993). Learners' difficulty with understanding rational numbers has several sources. An example can be found in the research of Siegler, Fazio, Bailey, and Zhou (2013) who point at the confusable properties concerning the arithmetic operations with rational numbers. They give the example that adding and subtracting fractions with the same denominator will result in a fraction with the same denominator, whereas this is not the case for multiplication and division. This leads to mistakes such as " $2 / 5 * 3 / 5=6 / 5$ ". Another important source of the difficulties learners have with the understanding of rational numbers is the natural number bias. An active field of research focused on this phenomenon (e.g. De Wolf \& Vosniadou, 2011; Obersteiner, Van Dooren, Van Hoof, \& Verschaffel, 2013; Vamvakoussi, Christou, Mertens, \& Van Dooren, 2011; Vamvakoussi et al., 2012; Vamvakoussi \& Vosniadou, 2004; Van Hoof, Lijnen, Verschaffel, \& Van Dooren; 2013; Van Hoof, Vandewalle, Verschaffel, \& Van Dooren, 2014). As this is also the background of the current paper, we will provide a more elaborate explanation of the natural number bias in the next section.

\section{Natural Number Bias}

The natural number bias is described as the (inappropriate) application of natural number features in rational number tasks (e.g. Van Hoof et al., 2014). While the origin of the natural number bias is still a matter of debate, there is large consensus in the literature that before children are introduced to rational numbers, they already have formed an intuitive idea of what a number is, which is based on natural numbers (Smith, Solomon, \& Carey, 2005, Vamvakoussi \& Vosniadou, 2010). Indeed, in their daily experiences, children encounter natural numbers much more often than rational numbers (one example is finger counting). This intuitive idea of numbers 
as natural numbers is confirmed and systematized by learners' first years of mathematics education (Greer,

2004). When rational numbers are then introduced in the classroom (mostly in the middle years of primary education), the principles and features of natural numbers are no longer always applicable. When this is the case, learners are found to make systematic mistakes specifically in rational numbers tasks where reasoning purely in terms of natural numbers results in an incorrect solution. At the same time, much higher accuracy levels are found in rational number tasks where reasoning merely in terms of natural numbers results in a correct solution. In the literature the former type of tasks, where reasoning in terms of natural numbers leads to an error, are called incongruent. For example: If learners are asked to indicate the largest number out of 0.25 and 0.7 , they may be inclined to rely on the knowledge that 25 is larger than 7 , as well as the knowledge that 0.25 has more digits than 0.7 , leading them to the incorrect answer that 0.25 is larger than 0.7 . Items where reasoning in terms of natural numbers leads to a correct answer, are called congruent items. An example of such an item is: If learners are asked to indicate the largest number out of 0.7 and 0.89 , relying on their natural number knowledge that 89 is larger than 7 , and/or that 0.89 has more digits will lead them to the correct answer that 0.89 is larger than 0.7 (Moss, 2005; Ni \& Zhou, 2005; Vamvakoussi \& Vosniadou, 2004).

In the research literature, three main aspects are distinguished in which the properties of natural numbers are inappropriately applied to rational numbers: their dense structure, their numerical size, and the effect of operations.

The first aspect concerns the structure of natural and rational numbers. Natural numbers are characterized by discreteness: You can always point out the successor number of any given number (for example: after 4 comes 5). Rational numbers, on the contrary, are characterized by a dense structure: There is no such thing as a successor number of a given rational number, as there are always infinitely many numbers between any two rational numbers. Many learners have difficulties understanding this difference in structure between natural and rational numbers. An illustration of this can be found in the study of Vamvakoussi et al. (2011) who found that only $28.3 \%$ of Greek and Flemish $9^{\text {th }}$ graders answered correctly that there are always infinitely many numbers between two given numbers and that these numbers can have both a fraction and a decimal form. Further, in an interview study with $9^{\text {th }}$ graders, Vamvakoussi and Vosniadou (2004) investigated learners' understanding of the dense structure of rational numbers. Their results showed that even in $9^{\text {th }}$ grade, many learners still have a naive idea of the structure of rational numbers. For example, more than half of the learners stated that there is only one number between $3 / 8$ and $5 / 8$.

The second aspect is related to the numerical size of rational numbers. As stated by Gabriel et al. (2013), 
learners' erroneous reasoning about the size of rational numbers can be most often attributed to the (wrong) idea

$$
\text { increases. One of the utterances relates to mistakes in decimal number comparison tasks, where learners have the }
$$
wrong assumption that, as is the case with natural numbers, "longer decimals are larger" and "shorter decimals are smaller" (Resnick et al., 1989). For example, in the study of Smith et al. (2005), 50 upper elementary school children were interviewed about several aspects of rational number understanding. Common mistakes were for example that learners incorrectly assumed that 0.65 was larger than 0.8 , because 65 is larger than 8 , and that 2.09 was larger than 2.9 because 209 is larger than 29 (while other learners argued that both numbers are equally large because the zero does not matter). In fraction comparison tasks, erroneous answers occur because learners' wrongly assume "that a fraction's numerical value increases when its denominator, numerator, or both increase" (Mamede, Nunes, \& Bryant, 2005; Meert, Grégoire, \& Noël, 2010). In a study of Clarke and Roche (2009) $6^{\text {th }}$ graders were interviewed on eight fraction comparison tasks. Their results showed that $77 \%$ of the learners answered correctly to the congruent task: "Which is the larger number: $3 / 8$ or $7 / 8$ ?". At the same time, only $37 \%$ of the same group of learners was accurate in solving the incongruent task: "Which is the larger number: 4/7 or 4/5?". Their study clearly shows that many learners focus on each part of a fraction separately to decide which fraction is the larger one instead of focusing on the whole numerical value of the fraction.

The third aspect of the natural number bias concerns the effect of arithmetic operations. Certain characteristics of operations with natural numbers are no longer applicable in the case of rational numbers. Indeed, addition and multiplication with natural numbers will always result in something larger while division and subtraction will always result in something smaller. However, these rules do not longer necessarily apply in the case of rational numbers (for example $0.4 * 9$ will result in an outcome smaller than 9), but learners still wrongly assume them to be true (Hasemann, 1981, Vamvakoussi et al., 2012). For instance, Van Hoof et al. (2014) asked $8^{\text {th }}$, 10 ${ }^{\text {th }}$, and $12^{\text {th }}$ graders to judge the correctness of algebraic expressions that addressed the effect of operations. An example of a congruent item was " $\mathrm{x} / 4<\mathrm{x}$ " which can be true both when $\mathrm{x}$ is a rational number, but also when $\mathrm{x}$ is a natural number. An example of an incongruent item was " $3<3 / x$ ", in which learners need to inhibit the natural number rule that division always make smaller and think of a rational number between zero and one to realize that the expression can be true. Clear evidence for an overall natural number bias was found in the higher accuracy levels on congruent items $(80.2 \%)$ than on incongruent items $(64.9 \%)$.

\section{Conceptual Change Theory}


In line with the above, a theoretical framework that has been frequently used to explain the natural number bias

is the conceptual change theory, and more specifically Vosniadou's framework theory approach towards conceptual change (Vosniadou, 1994; Vosniadou, Vamvakoussi, \& Skopeliti, 2008). This theory was originally proposed to explain learners' misconceptions in various science domains, but has afterwards also been applied to learning mathematics (Vamvakoussi, Vosniadou, \& Van Dooren, 2013). The main assumption of this theory is that learners gradually tend to organize their daily experiences in quite coherent framework theories (Vamvakoussi \& Vosniadou, 2010). These framework theories are domain-specific conceptual structures that help learners explain and deal with new, unknown (problem) situations (Vamvakoussi et al., 2011). When learners are confronted with new information which is not in line with their framework theory, they will have more difficulties to understand this information than when the new information affirms or extends their initial framework theory (Vosniadou et al., 2008). In the former cases, conceptual change is needed: Learners need to accommodate their initial framework to the new incompatible information. This accommodation is typically not an all at once process. Learners often attempt to assimilate the new information without completely revising the assumptions of their initial framework theories, which often results in inconsistencies or misconceptions, which are explained as synthetic models (Vosniadou et al., 2008). Put differently, learners often undergo a partial conceptual change, which leads them to answer correctly in one new situation while answering incorrectly in another situation, depending on the specific features of the task. An illustration of a synthetic model is the situation where learners already understand that between any two decimal numbers there are infinitely many other decimal numbers but do not understand that this also holds for any two fractions (Vosniadou et al., 2008).

\section{The present study}

The overall goal of this study was to characterize the development of the natural number bias in all three aspects (density, size, and operations) across the wide span between $4^{\text {th }}$ and $12^{\text {th }}$ grade. By doing so, we addressed various issues that - despite the extensive attention that the topic of rational number understanding recently has received - were not covered by research so far.

First, the natural number bias has amply been studied in separate age groups, be it elementary school students (e.g., Gómez, Jiménez, Bobadilla, Reyes, \& Dartnell, 2014), secondary school students (Stafylidou \& Vosniadou, 2004), or adults (e.g., Dewolf \& Vosniadou, 2011; Vamvakoussi et al., 2012). However, the evolution over a wider age range spanning primary and secondary education has not been addressed in research so far.

Second, while the natural number bias has been thoroughly investigated both with items involving rational 
numbers in their decimal form and in their fractional form, to the best of our knowledge, no study has yet

Third, previous research has typically focused on the three aforementioned aspects (density, size and operations) separately, which makes it difficult to compare the strength of the various aspects of the natural number bias at a given age. The only study we know of that included all the aspects is the one by Vamvakoussi et al. (2012) with adult participants. Clear evidence for the natural number bias was found in the higher accuracy levels of congruent than incongruent tasks for density and operations, while for size tasks there was no accuracy difference but only an effect in the higher reaction times participants needed to correctly solve incongruent size tasks in comparison with congruent size tasks. However, Vamvakoussi et al. (2012) only used a limited number of items, and the three aspects were not systematically and directly compared with each other in one overall analysis. So, no conclusions could be made about the relative strength of each aspect of the natural number bias. For the above three reasons, the major goal of the current study was to characterize the development of the natural number bias in all three aspects (density, size, and operations) across the span between $4^{\text {th }}$ and $12^{\text {th }}$ grade. However, since no test instrument was available to measure this natural number bias, a secondary goal of our study was to create a comprehensive paper-and-pencil test that includes a sufficient number of congruent as well as incongruent items about density, size, and operations, both in their decimal number and fraction form. We administered this paper-and-pencil test to learners from $4^{\text {th }}$ until $12^{\text {th }}$ grade, with the aim to investigate:

- The overall occurrence of a natural number bias (as evidenced by a higher performance on the congruent than on the incongruent items);

- $\quad$ The relative strength of this bias in the decimal vs. fraction format;

- The relative strength of the natural number bias across the density, size, and operations aspects of rational number understanding.

- The evolution with age of the natural number bias as a whole and specifically within each of the three aspects.

\section{Method}

\section{Participants}

Data were collected in 21 schools (nine primary schools and 12 secondary schools) from different parts of Flanders, Belgium. This resulted in a representative sample of 1343 learners distributed over $4^{\text {th }}$ grade $(n=213)$, $6^{\text {th }}$ grade $(n=230), 8^{\text {th }}$ grade $(n=293), 10^{\text {th }}$ grade $(n=302)$, and $12^{\text {th }}$ grade $(n=305)$. In Flanders, the instruction in 
the mathematics class on rational numbers typically starts in the $3^{\text {rd }}$ grade. To make sure learners were able to the Flemish educational standards and curricula (Gemeenschapsonderwijs, 2014; Vlaams Ministerie van Onderwijs en Vorming, 2011a) indicate that various aspects of rational numbers are recurrently addressed throughout the different years of primary and secondary education. In secondary education, most attention is spent to this topic in the first years, where the size of rational numbers, their representations with their mutual relations, and computation with rational numbers are extensively treated. In the upper years of secondary school learners still need to use rational numbers frequently, but there is no explicit instructional attention to the subject anymore (Vlaams Ministerie van Onderwijs en Vorming, 2011b).

\section{Design}

Starting from a broad literature review and an exploration of the Flemish mathematics curriculum, a comprehensive paper-and-pencil test (the Rational Number Sense Test, further abbreviated as 'RNST') was constructed with the aim to measure learners' natural number bias in rational number tasks. The test contained items addressing the three aforementioned aspects of the natural number bias (density, size, and operations), with items presented in fraction or decimal form or using a combination of both. The test further contained open and multiple choice questions and items of a varying difficulty degree for each of the aspects, in order to tap the full range of learners' natural number bias. In this study we report data from 63 items that were solved by learners from every grade. In total there were 15 density items ${ }^{1}$ ( 2 congruent and 13 incongruent), 33 size items (15 congruent and 18 incongruent), and 15 operations items ( 2 congruent and 13 incongruent). Further, 37 items involved fractions, 23 decimal numbers, and 3 items allowed a fraction or a decimal number as an answer. Examples of congruent and incongruent items are given in Table 1. The full test can be found in Appendix. Because the goal of the present study was to directly compare and investigate the development of the natural number bias in rational number tasks throughout the elementary and secondary school curriculum, we will report only the data from the 63 items that were in common to learners in all age groups. The entire RNST, however, contained 177 items, because with increasing grade, additional items were included to tap even more advanced understanding of rational numbers.

\footnotetext{
${ }^{1}$ The only exception is the test of the $4^{\text {th }}$ graders. Because the dense structure of rational numbers is only briefly introduced in elementary school in Flanders, only a limited number of density tasks (four) were provided in the test of the $4^{\text {th }}$ graders.
} 
Table 1

Examples of test items

\begin{tabular}{lll}
\hline & Congruent item & Incongruent item \\
\hline Density & Write a number between $1 / 4$ and $3 / 4$ & Write a number between 3.49 and \\
& & 3.50 \\
Size & Choose the largest number: & Choose the largest number: \\
& $14 / 18$ or $29 / 31$ & $3 / 9$ or $2 / 5$ \\
Operations & Is $50 * 3 / 2$ bigger or smaller than & Is $72 * 0.99$ bigger or smaller than \\
& $50 ?$ & $72 ?$ \\
\hline
\end{tabular}

\section{Analysis}

Because we had a repeated measures design, data were analyzed using the Generalized Estimation of Equations (GEE) in order to correct for repeated (and probably correlated) measures within participants (Liang \& Zeger, 1986). Learners' accuracy on a specific item was the dependent variable. Because of the dichotomous nature of this variable, we used logistic regression to model the probability that a correct answer was given to a specific item. The degree of difference in accuracy on the congruent versus incongruent items was seen as an indicator of the strength of the natural number bias. As such, we expected our analysis to point out a main effect of congruency indicating better performance on congruent than incongruent items. Besides investigating the congruency effect, we also investigated the interaction with the various other variables in the study, i.e. the representational format of the items, the aspect of the natural number bias dealt with, and learners' grade level.

\section{Results}

The reliability of the test instrument was high (Cronbach's alpha $=.87)$. The high reliability of the test was found in every grade separately as well $\left(4^{\text {th }}\right.$ grade: Cronbach's alpha $=.87,6^{\text {th }}$ grade: Cronbach's alpha $=.88,8^{\text {th }}$ grade: Cronbach's alpha $=.83,10^{\text {th }}$ grade: Cronbach's alpha $=.84$, and $12^{\text {th }}$ grade: Cronbach's alpha $=.83$ ).

\section{Congruency Main Effect}


A significant main effect of congruency was found $X^{2}(1, N=1343)=1456,13, p<.001$. The accuracy level for congruent items $(87.9 \%)$ was significantly higher than for incongruent items $(66.8 \%)$ for the whole group of participants, confirming an overall occurrence of a natural number bias.

\section{Congruency x Representation Interaction Effect}

No significant interaction effect between representation and congruency could be found, $X^{2}(1, N=1343)=0.03$, $p=.87^{2}$. This suggests that the natural number bias was equally strong in rational number tasks with decimal numbers as in rational number tasks with fractions. Pairwise comparisons demonstrated significantly higher accuracy levels for congruent items compared to incongruent items for rational number tasks with decimal numbers $(88.5 \%$ vs. $68.1 \%, p<.001)$ as well as for rational number tasks with fractions $(87.6 \%$ vs. $66.0 \%, p<$ .001). The finding that the natural number bias was equally strong in rational number tasks with decimal numbers as in rational number tasks with fractions is also visible in the odds ratios and their $95 \%$ confidence intervals $(\mathrm{OR}=3.61,95 \% \mathrm{CI}[3.32,3.92]$ for decimal numbers and $\mathrm{OR}=3.63,95 \% \mathrm{CI}[3.43,3.85]$ for fractions).

\section{Congruency x Aspect Interaction Effect}

A significant interaction effect between congruency and aspect was found $X^{2}(3, N=1343)=439.86, p<.001$, indicating that the natural number bias was not equally strong for each of the three aspects. Pairwise comparisons demonstrated significantly higher accuracy levels for congruent items in comparison with incongruent items for each aspect: $92.5 \%$ vs. $51.9 \%, p<.001$ for density, $87.9 \%$ vs. $83.1 \%, p<.001$ for size, and $84.7 \%$ vs. $68.3 \%, p<.001$ for operations. The odds ratios and their $95 \%$ confidence intervals showed that the natural number bias was weakest in size tasks $(\mathrm{OR}=1.48,95 \% \mathrm{CI}[1.40,1.57])$, somewhat larger in operations tasks $(\mathrm{OR}=1.66,95 \% \mathrm{CI}[1.58,1.74])$ and clearly largest in density tasks $(\mathrm{OR}=11.48,95 \% \mathrm{CI}$ $[10.01,13.17])$.

\section{Congruency x Grade Interaction Effect}

A significant interaction effect between congruency and grade was found $X^{2}(8, N=1343)=998.95, p<.001$, indicating that the natural number bias was not equally strong in every grade although higher accuracy levels for

\footnotetext{
${ }^{2}$ Because there were only 3 items that consisted of a combination of fractions and decimal numbers or of an open question in which learners could answer with a fraction or a decimal number, these 3 items are not discussed in this part of the analysis and we only looked at the difference between items with fractions and items with decimal numbers.
} 
congruent items than incongruent items were found in each grade level: for $4^{\text {th }}(78.7 \%$ vs. $41.7 \%, p<.001), 6^{\text {th }}$ $(88.8 \%$ vs. $58.3 \%, p<.001), 8^{\text {th }}(88.9 \%$ vs. $67.5 \%, p<.001), 10^{\text {th }}(90.0 \%$ vs. $78.1 \%, p<.001)$, and $12^{\text {th }}$ graders (93.0\% vs. $85.4 \%, p<.001)$. The odds ratios and their $95 \%$ confidence intervals (see Figure 1 ) showed that the strength of the natural number bias was not significantly different for $4^{\text {th }}$ graders $(\mathrm{OR}=5.16,95 \% \mathrm{CI}$ $[4.72,5.63])$ and $6^{\text {th }}$ graders $(\mathrm{OR}=5.66,95 \%$ CI $[5.12,6.25])$. However, the natural number bias was significantly weaker in $8^{\text {th }}$ graders $(\mathrm{OR}=3.85,95 \%$ CI $[3.45,4.31])$ and even significantly weaker in $10^{\text {th }}$ graders $(\mathrm{OR}=2.52,95 \% \mathrm{CI}[2.24,2.83])$ and $12^{\text {th }}$ graders $(\mathrm{OR}=2.26,95 \% \mathrm{CI}[1.98,2.59])$. The strength of the natural number bias did not significantly differ between these latter two grades.

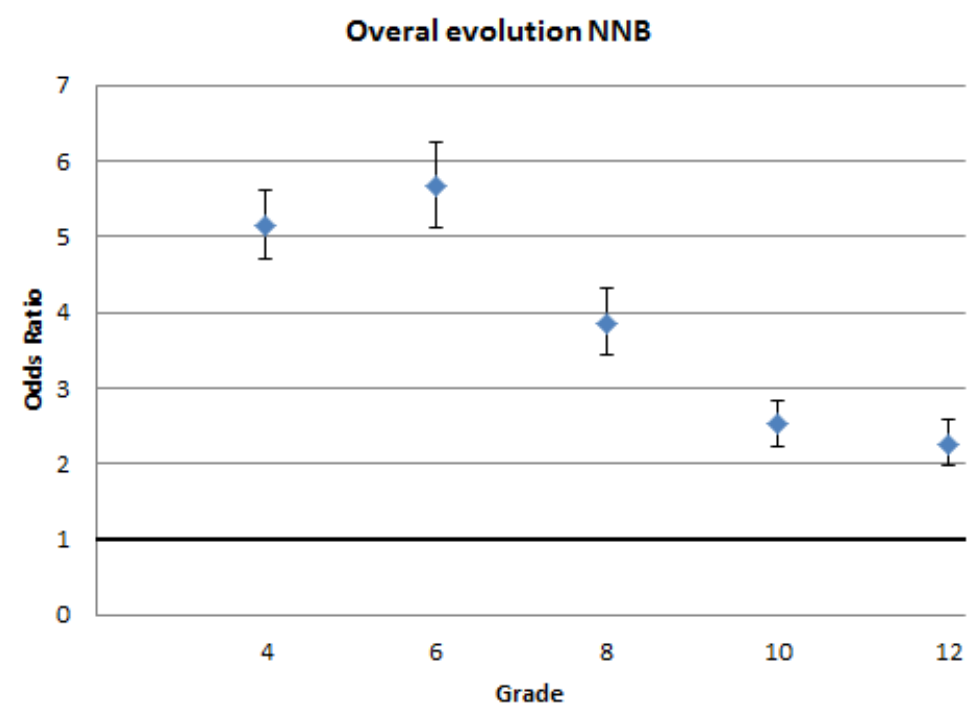

Figure 1. Overall evolution of the strength of the natural number bias as represented by the odds ratios (an odds ratio of 1 indicates an absence of a bias).

\section{Congruency x Grade Interaction Effect for Every Aspect}

Density.

Important to note is that the dense structure of rational numbers is only briefly introduced in elementary school in Flanders. Therefore, only a limited number of density tasks were provided in the test of the $4^{\text {th }}$ graders. Consequently, the data from the density tasks of the $4^{\text {th }}$ graders were not used in the current analysis.

There was a significant interaction effect between congruency and grade $X^{2}(3, N=1130)=15.14, p<.01$. Pairwise comparisons demonstrated significantly higher accuracy levels on congruent than on incongruent density items for $6^{\text {th }}(89.1 \%$ vs. $24.2 \%, p<.001), 8^{\text {th }}(94.0 \%$ vs. $39.3 \%, p<.001), 10^{\text {th }}(95.4 \%$ vs. $63.8 \%, p<$ $.001)$, and $12^{\text {th }}$ graders $(95.8 \%$ vs. $74.0 \%, p<.001)$. The odds ratios showed that the natural number bias was 
very strong in all grades: $6^{\text {th }}$ graders $(\mathrm{OR}=25.71,95 \% \mathrm{CI}[18.95,34.89]), 8^{\text {th }}$ graders $(\mathrm{OR}=24.02,95 \% \mathrm{CI}$ $[15.77,36.58]), 10^{\text {th }}$ graders $(\mathrm{OR}=11.69,95 \% \mathrm{CI}[7.33,18.65])$, and $12^{\text {th }}$ graders $(\mathrm{OR}=8.05,95 \% \mathrm{CI}[4.92$, 13.18]). These confidence intervals indicated that although the strength of the natural number bias for density does not significantly differ from one age group to the next one, the general trend was that the strength of the natural number bias decreased with grade (see Figure 2a). 


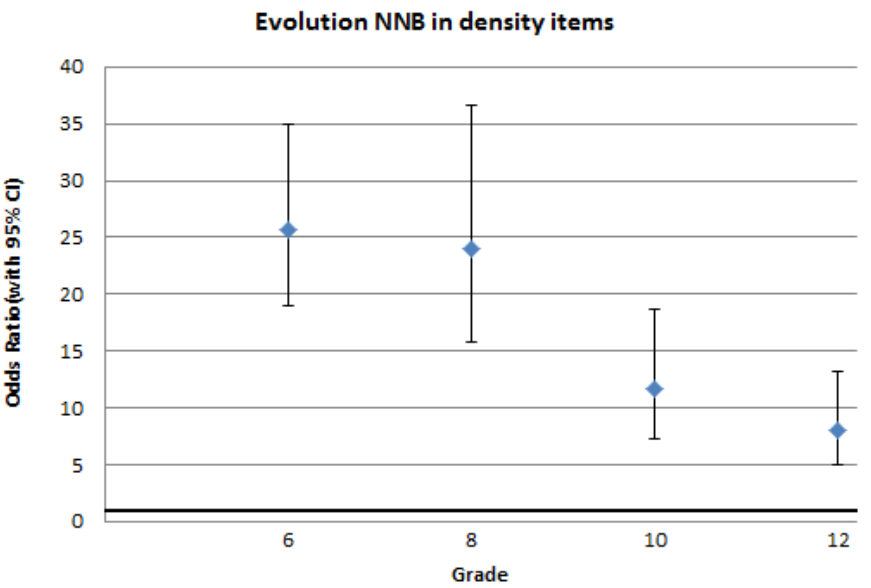

Figure 2a.

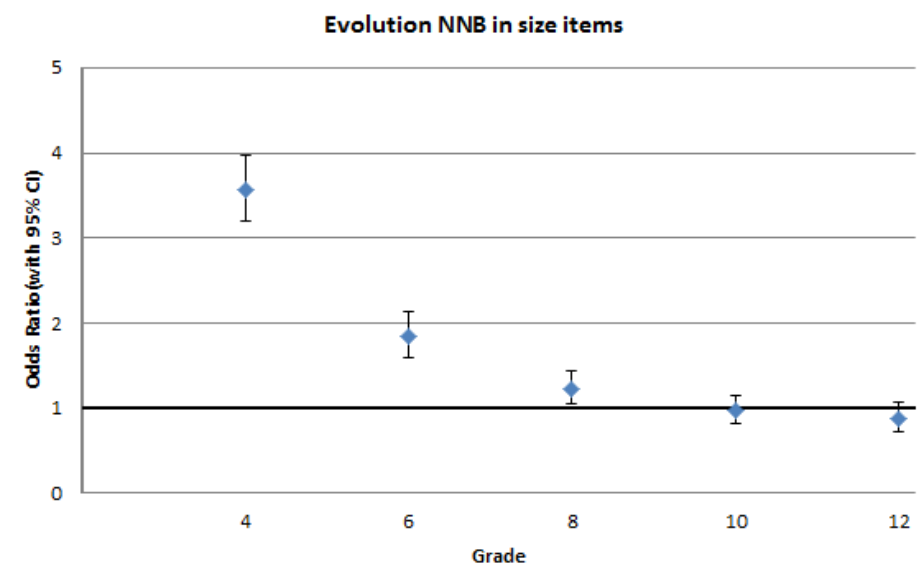

Figure $2 b$.

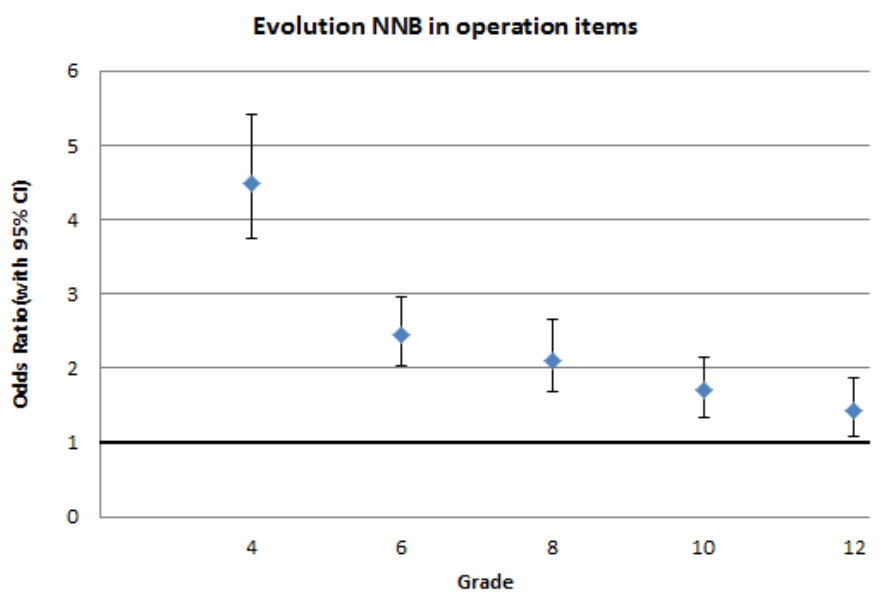

Figure 2c.

Figure 2. Evolution of the strength of the natural number bias in density (2a), size (2b), and operations items (2c) as represented by the odds ratios (an odds ratio of 1 indicates an absence of a bias).

Size. 
There was a significant interaction effect between congruency and grade, $X^{2}(4, N=1343)=80.81, p<.001$.

Pairwise comparisons yielded significantly higher accuracy levels on congruent size items in comparison with incongruent size items for $4^{\text {th }}(79.8 \%$ vs. $52.6 \%, p<.001), 6^{\text {th }}(91.5 \%$ vs. $85.3 \%, p<.001)$, and $8^{\text {th }}$ graders $(89.7 \%$ vs. $87.6 \%, p=.04)$, but not in $10^{\text {th }}(90.5 \%$ vs. $90.8 \%, p=.74)$ and $12^{\text {th }}$ graders $(93.4 \%$ vs. $94.2 \%, p=$ .29). The odds ratios showed (see Figure $2 b$ ) that the strength of the natural number bias was largest in $4^{\text {th }}$ graders $(\mathrm{OR}=3.56,95 \% \mathrm{CI}[3.20,3.97])$, somewhat smaller in $6^{\text {th }}$ graders $(\mathrm{OR}=1.85,95 \% \mathrm{CI}[1.60,2.14]$, and nearly absent in $8^{\text {th }}$ graders $(\mathrm{OR}=1.23,95 \% \mathrm{CI}[1.05,1.44])$. No natural number bias for size items was found in the odds ratio of the $10^{\text {th }}(\mathrm{OR}=0.97,95 \% \mathrm{CI}[0.82,1.15])$ and $12^{\text {th }}$ graders $(\mathrm{OR}=0.87,95 \% \mathrm{CI}[0.72,1.07])$.

\section{Operations.}

There was a significant interaction effect between congruency and grade, $X^{2}(4, N=1343)=80.90, p<.001$. Pairwise comparisons demonstrated significantly higher accuracy levels on congruent operations items in comparison with incongruent operations items for all grade levels: $4^{\text {th }}$ graders $(68.5 \%$ vs. $32.6 \%, p<.001), 6^{\text {th }}$ graders $(74.9 \%$ vs. $54.9 \%, p<.001), 8^{\text {th }}$ graders $(81.7 \%$ vs. $67.9 \%, p<.001), 10^{\text {th }}$ graders $(83.7 \%$ vs. $75.0 \%, p$ $<.001)$, and $12^{\text {th }}$ graders $(88.8 \%$ vs. $84.7 \%, p=.01)$. The odds ratio showed that the strength of the natural number bias was largest in $4^{\text {th }}$ graders $(\mathrm{OR}=4.49,95 \% \mathrm{CI}[3.74,5.41])$, somewhat smaller in $6^{\text {th }}$ graders $(\mathrm{OR}=$ $2.45,95 \% \mathrm{CI}[2.04,2.96], 8^{\text {th }}$ graders $(\mathrm{OR}=2.11,95 \%$ CI $[1.68,2.65])$, and $10^{\text {th }}$ graders $(\mathrm{OR}=1.71,95 \% \mathrm{CI}$ $[1.35,2.16])$, and nearly absent in $12^{\text {th }}$ graders $(\mathrm{OR}=1.43,95 \% \mathrm{CI}[1.08,1.87])$. As for the density items, the strength of the natural number bias did not significantly decrease between every grade. However, the general trend was that the strength of the natural number bias decreases with grade (see Figure 2c).

\section{Conclusion and Discussion}

A good understanding of rational numbers is an essential part of mathematical literacy. However, children and even adults have difficulty with the understanding of the different aspects of rational numbers. The natural number bias has been found to explain a large part of this difficulty. Although a large body of literature already exists on the natural number bias, this literature is quite fragmented. The present study aimed at characterizing the development of the natural number bias for all three aspects of it that have been distinguished in the research literature and across the wide span between $4^{\text {th }}$ and $12^{\text {th }}$ grade. To do so, a secondary aim of the study was to construct a single test instrument that comprises all three aspects of it, both in their decimal and fractional representation.

Based on the existing literature and an analysis of the Flemish curriculum, we created and validated a 
comprehensive test instrument that enabled to systematically and directly compare the strength of the natural numbers) between $4^{\text {th }}$ and $12^{\text {th }}$ grade. The fact that we succeeded in constructing a comprehensive test instrument with a high overall reliability in all five grades, and with systematically substantially higher accuracies on items that we characterized as congruent than on items that we characterized as incongruent suggests that this test measures one construct, namely learners' natural number bias.

In what follows, we will first report the most important results and conclusions of this study. Second, an important methodological implication together with some methodological shortcomings of the study will be discussed. Third, we will point at some suggestions for future research. At last, an important educational implication of this study will be discussed.

Using the new test instrument in a large group of $4^{\text {th }}$ to $12^{\text {th }}$ graders, it was first of all found that this bias was equally strong in tasks with decimal numbers as with fractions. Given that the relative strength of the natural number bias was never directly and systematically compared across these two representations, this is an interesting finding, particularly because the available theoretical and empirical literature contains evidence that different kinds of natural number-based errors may occur in items involving these two representations. For example: For the aspect of size, learners' misconception about the size of decimal numbers is largely based on their length ("longer decimals are larger" and "shorter decimals are smaller") (e.g. Resnick et al., 1989), while in the case of fractions misconceptions are (largely) based on the numerical value of each of the components of the fractions (“a fraction's numerical value increases when its denominator, numerator, or both increase") (e.g. Mamede et al., 2005). Similarly, for the density aspect, numbers situated between two other decimal numbers can be found by simply extending these decimal numbers with zeros, while finding numbers between two given fractions requires other approaches. So, even though different difficulties seem to come into play in solving items in decimal numbers and fractions, we found no difference in the strength of the natural number bias between these two representation forms.

Second, an overall decrease of the strength of the natural number bias was found with grade. While the strength of the natural number bias was equally large in $4^{\text {th }}$ and $6^{\text {th }}$ graders, it was significantly lower in $8^{\text {th }}$ graders and even lower in $10^{\text {th }}$ graders. No significant difference was observed in the strength of the natural number bias between $10^{\text {th }}$ and $12^{\text {th }}$ graders. We can conclude from these results that learners' rational number sense increases with grade and that it develops over a period of at least six years. Further, we learn from these results that the development of learners' rational number sense does not develop continuously, but that there are periods where 
this goes faster and other periods where it stagnates, for example between $10^{\text {th }}$ and $12^{\text {th }}$ grade. This stagnation still be found in $12^{\text {th }}$ grade in density and operations items.

Third, results showed that the natural number bias was weakest in size tasks, somewhat stronger in operations tasks, but by far the strongest in density tasks. This is in line with previous research (see for example Vamvakoussi et al., 2012).

Fourth, subsequent to the above, there was a gradual decrease in the strength of the natural number bias for density and operations tasks throughout primary and secondary education, while for the size aspect the bias had already almost disappeared in grade eight. Thus, while an evolution can be found in learners' understanding of all three aspects of the natural number bias, they continue to struggle particularly with the operations and density aspect. Especially the dense structure of rational numbers remains difficult to grasp, even for higher secondary school students.

Besides the above-mentioned theoretical findings and conclusions, the present study also resulted in another valuable outcome, namely a valid and reliable test instrument. As stated above, while there have been already studies within the three aforementioned aspects of the natural number bias (density, size and operation), there was no test yet that addressed all of them in an integrated manner. In this study, we have created a valid and reliable test instrument (the RNST) that measures learners' natural number bias in rational number tasks, and this test can be useful in future research in this domain. This RNST can, for example, be used to conduct (internationally) comparative research. It can further be used as effectiveness measure in intervention studies aimed at improving learners' rational number sense. At last, the RNST can be used to investigate the relation between learners' rational number sense and other aspects of learners' number sense and/or other learner characteristics. An example can be found in the study of Van Hoof, Verschaffel, and Van Dooren (submitted), in which the RNST was used to further investigate the relation between learners' natural and rational number sense, departing from the study of Bailey, Siegler, and Geary (2014). Based on the data of $1306^{\text {th }}$ graders, Van Hoof et al. found positive correlations between learners' natural and rational number sense, which confirms the findings of Bailey et al. (2014). Further, the relation between learners' natural and rational sense was found even when they focused on incongruent rational number tasks, when they included items from all three aspects of rational number knowledge (density, size, and operations), and when they used items both in their fractional and decimal form. However, the relation between both variables was always found to be completely mediated by learners' general mathematics achievement. 
We now turn to some methodological limitations of the study and make suggestions for further research. First, next to a cross-sectional design, future research would benefit from longitudinal designs to capture how learners' individual rational number sense evolves over time, using latent profile analysis and latent transition analysis. In a recent longitudinal study of McMullen, Laakkonen, Hannula-Sormunen, and Lehtinen (2014), these latter statistical techniques have already been used successfully to describe learners' processes of conceptual change in rational number understanding. In their study, conceptual knowledge of the dense structure and the size of rational numbers was measured from 263 upper elementary school children over a one-year time period. A first finding was that conceptual knowledge of size of rational numbers is necessary but not sufficient for successful conceptual change in the aspect of density. Second, participants only showed limited conceptual change in the aspects of size and density. However, these authors, in their turn, argue that still more research is needed to be able to confirm their results. Firstly, their finding that participants only showed limited conceptual change can be explained by the fact that they included elementary school students and moreover only followed them for one year. This asks for enlarging the time frame in which the learners are followed and for including older, secondary school students. At last, only the aspects of size and density were investigated in their study. Using the test instrument developed and used in the context of our study, a more comprehensive description of learners' rational number sense can be acquired.

A second limitation of our study was that we only used performance data collected in a collective paper-andpencil test. With a view to investigate the interference of learners' natural number knowledge in rational number tasks, it would be interesting to complement these performance data with data about learners' reaction times. As shown by numerous studies (see for example Vamvakoussi et al., 2012), reaction time data are effective in investigating the natural number bias. The core finding of these reaction time studies is that it takes more time to respond correctly to incongruent than to congruent tasks. So, the main advantage of reaction times is that they still can shed light on the natural number bias even in learners who no longer make errors.

We finally turn to an important educational implication that emerges from this study. Given that the understanding of rational numbers has been shown to relate to later mathematics achievement, it is quite worrying that the majority of learners have troubles understanding the several aspects of rational numbers, some of which even last until the end of secondary school. Consequently, the acquisition of rational number understanding - and particularly of the understanding of the differences with natural numbers - deserves more attention in the mathematics class. In this respect, we note that errors committed by learners may be partly caused by formal instruction, or at least by the fact that they are not sufficiently addressed by instruction. Debou 
and Verschetze (2012) systematically investigated the three most often used textbooks for elementary school mathematics in Flanders. Their analysis showed that textbooks pay almost no explicit attention to the (conceptual) differences between natural and rational numbers, but rather tend to only point to similarities between both. We believe that if textbook designers and teachers have a thorough understanding of the natural number bias, they will be better able to address the natural number bias, for instance by pointing the learners systematically to differences between natural numbers and rational numbers.

A more specific educational implication is that especially more attention should go to the dense structure of rational numbers in the classrooms given the fact that our results showed that although we found a continuous growth in learners' understanding of the dense structure of rational numbers, upper secondary school students still seem to seriously struggle with it. 


\section{References}

Clarke, D. M., \& Roche, A. (2009). Students` fraction comparison strategies as a window into robust understanding and possible pointers for instruction. Educational Studies in Mathematics, 72, 127-138. doi:10.10007/s10649-009-9198-9.

Cramer, K. A., Post, T. R., \& delMas, R. C. (2002). Initial fraction learning by fourth- and fifth- grade students: A comparison of the effects of using commercial curricula with the effects of using the rational number project curriculum. Journal for Research in Mathematics Education, 33, 111-144.

Debou, E., \& Verschetze, L. (2012). De overgang van natuurlijke naar rationale getallen. Een curriculumanalyse van drie Vlaamse wiskundemethoden [From natural to rational numbers. A curriculum analysis of 3 Flemish mathematics textbooks] (Unpublished master's thesis). Katholieke Universiteit Leuven, Faculteit Psychologie en Pedagogische Wetenschappen, Belgium.

De Wolf, M., \& Vosniadou, S. (2011). The whole number bias in fraction magnitude comparisons with adults. In L. Carlson, C. Hoelscher, \& T. F. Shipley (Eds.), Proceedings of the 33rd Annual Conference of the Cognitive Science Society (pp. 1751-1756). Austin, TX: Cognitive Science Society.

Gabriel, F., Coché, F., Szucs, D., Carette, V., Rey, B., \& Content, A. (2013). A componential view of children’s difficulties in learning fractions. Frontiers in Psychology, 4, 1-12. doi:10.3389/fpsyg.2013.00715

Gemeenschapsonderwijs. (2014). Leerplannen. Geraadpleegd op http://www.gemeenschapsonderwijs.be/sites/portaal_nieuw/Prikbordvoorleerkrachten/Basisonderwijs/leerpla nnen/Leerplannen\%2020102011/Wiskunde\%20-\%20LO.pdf

Gómez, D., Jiménez, A., Bobadilla, R., Reyes, C., \& Dartnell, P. (2014). Exploring fraction comparison in school children. Enero, 10, 1-10.

Greer, B. (2004). The growth of mathematics through conceptual restructuring. Learning \& Instruction, 14, 541548. doi:10.1016/j.learninstruc.2004.06.018

Hasemann, C. (1981). On difficulties with fractions. Educational Studies in Mathematics, 12, 171-187. doi:10.1007/BF00386047

Liang, K. Y., \& Zeger, S. L. (1986). Longitudinal data analysis using generalized linear models. Biometrika, 73, 13-22. doi:10.1093/biomet/73.1.13 
Mamede, E., Nunes, T., \& Bryant, P. (2005). The equivalence and ordering of fractions in part-whole and quotient situations. In H. L. Chick \& J. L. Vincent (Eds.), Proceedings of the 29th Conference of the International Group for the Psychology of Mathematics Education: Vol. 3. (pp. 281-288). Melbourne, Australia: PME.

Mazzocco, M. M. M., \& Devlin, K. T. (2008). Parts and 'holes': Gaps in rational number sense among children with vs. without mathematical learning disabilities. Developmental Science, 11, 681-691. doi:10.1111/j.14677687.2008.00717.x

McMullen, J., Laakkonen, E., Hannula-Sormunen, M. M., \& Lehtinen, E. (2014). Modeling the developmental trajectories of rational number concept(s): A latent variable approach. Learning and Instruction. Doi.10.1016/j.learninstruc.2013.12.004

Meert, G., J., Grégoire, J., \& Noël, M-P. (2010). Comparing the magnitude of two fractions with common components: Which representations are used by 10- and 12-year-olds? Journal of Experimental Child Psychology, 107, 244-259.

Moss, J. (2005). Pipes, tubes, and beakers: New approaches to teaching the rational-number system. In M. S. Donovan \& J. D. Bransford (Eds.), How students learn: Mathematics in the classroom (pp. 121-162). Washington, DC: National Academic Press.

Ni, Y., \& Zhou, Y.-D. (2005). Teaching and learning fraction and rational numbers: The origins and implications of whole number bias. Educational Psychologist, 40, 27-52.doi:10.1207/s15326985ep4001_3

Obersteiner, A., Van Dooren, W., Van Hoof, J., \& Verschaffel, L. (2013). The natural number bias and magnitude representation in fraction comparison by expert mathematicians. Learning and Instruction, 28, 6472. doi:10.1016/j.learninstruc.2013.05.003

Post, T., Cramer, K., Behr, M., Lesh, R., \& Harel, G. (1993). Curriculum implications of research on the learning, teaching and assessing of rational number concepts. In T. Carpenter, E. Fennema \& T. Romberg (Eds.), Rational numbers: An integration of research (pp. 327-361). Hillsdale, NJ: Lawrence Erlbaum.

Resnick, L. B., Nesher, P., Leonard, F., Magone, M., Omanson, S., \& Peled, I. (1989). Conceptual bases of arithmetic errors: The case of decimal fractions. Journal for Research in Mathematics Education, 20, 8-27. 
Siegler, R. S., Duncan, G. J., Davis-Kean, P. E., Duckworth, K., Claessens, A., Engel, M.,.. Chen, M. (2012). Early predictors of high school mathematics achievement. Psychological Science, 23, 691-697. doi:10.1177/0956797612440101

Siegler, R. S., Fazio, L. K., Bailey, D. H., \& Zhou, X. (2013). Fractions: the new frontier for theories of numerical development. Trends in Cognitive Science, 17, 13-19.

Smith, C. L., Solomon, G. E. A., \& Carey, S. (2005). Never getting to zero: Elementary school students' understanding of the infinite divisibility of number and matter. Cognitive Psychology, 51, 101-140. doi:10.1016/j.cogpsych.2005.03.001

Vamvakoussi, X., Christou, K. P., Mertens, L., \& Van Dooren, W. (2011). What fills the gap between discrete and dense? Greek and Flemish students' understanding of density. Learning and Instruction, 21, 676-685. doi:10.1016/j.learninstruc.2011.03.005

Vamvakoussi, X., Van Dooren, W., \& Verschaffel, L. (2012). Naturally biased? In search for reaction time evidence for a natural number bias in adults. The Journal of Mathematical Behavior, 31, 344-355. doi:10.1016/j.jmathb.2012.02.001

Vamvakoussi, X., \& Vosniadou, S. (2004). Understanding the structure of the set of rational numbers: A conceptual change approach. Learning and Instruction, 14, 453-467. doi:10.1016/j.learninstruc.2004.06.013

Vamvakoussi, X., \& Vosniadou, S. (2010). How many decimals are there between two fractions? Aspects of secondary school students ' understanding of rational numbers and their notation. Cognition and Instruction, 28, 181-209. doi:10.1080/07370001003676603

Vamvakoussi, X., Vosniadou, S., \& Van Dooren, W. (2013). The framework theory approach applied to mathematics learning. In S. Vosniadou (Ed.), International handbook of research on conceptual change (pp. 305-321). New York, NY: Routledge.

Van Hoof, J., Lijnen, T., Verschaffel, L., \& Van Dooren, W. (2013). Are secondary school students still hampered by the natural number bias? A reaction time study on fraction comparison tasks. Research in Mathematics Education, 15, 154-164. doi:10.1080/14794802.2013.797747

Van Hoof, J., Vandewalle, J., Verschaffel, L., \& Van Dooren, W. (2014). In search for the natural number bias in secondary school students' interpretation of the effect of arithmetical operations. Learning and Instruction. Advance online publication. doi:10.1016/j.learninstruc.2014.03.004 
Vlaams Ministerie van Onderwijs en Vorming. (2011a). Eindtermen wiskunde: secundair onderwijs, eerste graad A-stroom. Retrieved from http://ond.vlaanderen.be/dvo/secundair/1stegraad/astroom/eindtermen/wiskunde.htm.

Vlaams Ministerie van Onderwijs en Vorming. (2011b). Eindtermen wiskunde: secundair onderwijs, derde graad ASO. Retrieved from http://ond.vlaanderen.be/dvo/secundair/3degraad/aso/eindtermen/wiskunde.htm.

Vosniadou, S. (1994). Capturing and modelling the process of conceptual change. Learning and Instruction, 4, 45-69. doi:10.1016/0959-4752(94)90018-3

Vosniadou, S., Vamvakoussi, X., \& Skopeliti, I. (2008). The framework theory approach to conceptual change. In S. Vosniadou (Ed.), International handbook of research on conceptual change (pp. 3-34). Mahwah, NJ: Lawrence Erlbaum. 


\section{Appendix: Items included in the study}

Write a number between these two numbers. If you think that is not possible, write 'impossible'.
1) 8,9 and 8,15
2) 3,49 and 3,50
5) $\frac{1}{3}$ and $\frac{2}{3}$
6) $\frac{1}{8}$ and $\frac{1}{9}$
26) 2,5 and 2,7
28) $\frac{1}{4}$ and $\frac{3}{4}$

9) Write down two different numbers so that there are no other numbers in between those two numbers. If you think that is not possible, write 'impossible'.

How many numbers are there between:

10) 1,42 and 1,43

11) 1,9 and 1,40

14) $\frac{2}{5}$ and $\frac{3}{5}$

15) $\frac{1}{5}$ and $\frac{1}{7}$ ?

How many numbers are there between these numbers? Circle the best answer.

18) 0,7 and 0,9

19) 3,42 and 3,124

22) $\frac{1}{3}$ and $\frac{2}{3}$

23) $\frac{1}{6}$ and $\frac{1}{7}$

a) There is no number

b) There is a finite number of decimal numbers

c) There is a finite number of fractions

d) There are infinitely many decimal numbers

e) There are infinitely many fractions

f) There are infinitely many numbers, who can be presented both in their decimal form as in their fraction form

g) None of the above, I think that 
Order the following numbers from small to large. If two numbers are equally large, circle them to indicate that they are equally large.
30) $\frac{5}{6} \quad 1 \quad \frac{1}{7} \quad \frac{4}{3}$
67) $\frac{5}{100} \quad \frac{5}{10} \quad \frac{70}{100} \quad \frac{10}{10} \quad \frac{20}{100} \quad \frac{50}{100} \quad \frac{2}{10} \quad \frac{7}{100} \quad \frac{7}{10} \quad \frac{2}{100}$
73) $3,682 \quad 3,2 \quad 3,35$
$\begin{array}{lll}74) & 7,651 & 7,8\end{array}$
75) $\quad 0,5 \quad \frac{1}{4} \quad \frac{5}{10} \quad 0,356$

Circle the largest number
31) $\frac{2}{5}$ or $\frac{8}{7}$
46) $\frac{3}{2}$ or $\frac{9}{8}$
55) $\frac{2}{5}$ or $\frac{2}{7}$
65) $\frac{7}{5}$ or $\frac{2}{5}$
34) $\frac{7}{6}$ or $\frac{1}{3}$
49) $\frac{3}{2}$ or $\frac{8}{9}$
56) $\frac{3}{2}$ or $\frac{3}{6}$
66) $\frac{3}{7}$ or $\frac{4}{7}$
36) $\frac{5}{4}$ or $\frac{7}{5}$
50) $\frac{4}{2}$ or $\frac{9}{6}$
59) $\frac{2}{6}$ or $\frac{3}{6}$
68) 4,4 or 4,50
38) $\frac{8}{5}$ or $\frac{1}{3}$
51) $\frac{1}{3}$ or $\frac{1}{6}$
60) $\frac{5}{2}$ or $\frac{7}{2}$
69) 0,3 or 0,30
40) $\frac{4}{9}$ or $\frac{2}{7}$
52) $\frac{8}{7}$ or $\frac{8}{5}$
61) $\frac{4}{8}$ or $\frac{5}{8}$
70) 0,36 or 0,5
41) $\frac{3}{9}$ or $\frac{2}{5}$
53) $\frac{5}{10}$ or $\frac{5}{4}$
62) $\frac{3}{4}$ or $\frac{2}{4}$
71) 2,621 or 2,0687986
45) $\frac{2}{5}$ or $\frac{2}{3}$
54) $\frac{7}{2}$ or $\frac{7}{9}$
64) $\frac{6}{9}$ or $\frac{5}{9}$
72) 0,25 or 0,400

122)Without calculating the exact answer, do you think $72.0,99$ is bigger or smaller than 72 ?

127) Without calculating the exact answer, do you think $50.3 / 2$ is bigger or smaller than 50 ?

129) Without calculating the exact answer, do you think $21: 0,7$ is bigger or smaller than 21 ?

130) Without calculating the exact answer, do you think $40: 1 / 2$ is bigger or smaller than 40 ?

131) What is half of $1 / 8$ ?

134) Is it possible that the sum of two numbers is smaller than zero?
O Yes
O No

171) $0,46=0,4+\ldots$ 
173) $\quad 0,36-0,2=\ldots$

174) $\quad 0,500-\ldots=0,45$

Circle the correct operation you need to answer the following word problems.

175) 1 liter of lemon syrup is needed to make 15 liter of lemonade. How many lemonade can be made from 0.75 liter of lemon syrup?
A. $0,75: 15$
B. $15.0,75$
C. $15: 0,75$

176) The price of 1 kilogram gold is 15000 euro. What is the price of $1 / 5$ kilogram gold?
A. $15000: \frac{1}{5}$
B. $\frac{1}{5}: 15000$
C. $15000 \cdot \frac{1}{5}$

177) 12 friends bought 5 kilogram of cookies. If they want to equally divide the cookies, how many kilograms does each friend get?
A. $5: 12$
B. 5.12
C. $12: 5$

178) I had to pay 9 euro for $3 / 4$ kilogram candy. What is the price of 1 kilogram candy?
A. $9: \frac{3}{4}$
B. $9 \cdot \frac{3}{4}$
C. $\frac{3}{4}: 9$

179) If you know the walls of the bathroom are 3 meters high. How many rows of tiles do you need to cover the wall if you know the tiles have a height of 0.15 meters?
A. $3: 0,15$
B. $0,15.3$
C. $0,15: 3$ 